\title{
An open-label expanded access program of afatinib in EGFR tyrosine kinase inhibitor- naïve patients with locally advanced or metastatic non-small cell lung cancer harboring EGFR mutations
}

Keunchil Park ${ }^{1 *}$, Jin-Soo Kim², Joo-Hang Kim³ ${ }^{3}$ Young-Chul Kim ${ }^{4}$, Hoon-Gu Kim5 ${ }^{5}$ Eun Kyung Cho ${ }^{6}$, Jong-Youl Jin ${ }^{7}$, Miyoung Kim ${ }^{8}$, Angela Märten ${ }^{9}$ and Jin-Hyoung Kang ${ }^{10}$

\begin{abstract}
Background: Afatinib is approved globally for EGFR-TKI treatment-naive patients with EGFR mutation-positive nonsmall cell lung cancer (NSCLC). In this Korean expanded access program, we evaluated its 'real-world' safety and efficacy.

Methods: EGFR-TKI treatment-naïve patients with EGFR mutation-positive NSCLC received afatinib $40 \mathrm{mg} /$ day until disease progression or other withdrawal criteria. Dose reductions were permitted for adverse events (AEs). The primary endpoint was the number of patients with AEs (CTCAE version 3.0). Other endpoints included progressionfree survival (PFS), overall response rate (ORR), duration of response (DOR), and changes in investigator-assessed cancer-related symptoms.
\end{abstract}

Results: Eighty-eight patients received afatinib, including 27 (31\%) with brain metastases and 16 (18\%) with uncommon EGFR mutations. Median PFS was 17.0 months (95\% confidence interval [CI] 12.9-23.3 months). Grade 3 treatment-related AEs (TRAEs) were reported in 51 (58\%) patients; the most common were diarrhea (22\%) and rash/ acne (20\%). No grade > 3 TRAEs were reported. AEs leading to dose reduction occurred in 49 (56\%) patients. Treatment discontinuation due to TRAEs occurred in 4 (5\%) patients. ORR was $81 \%$ overall, $89 \%$ in patients with brain metastases, and 55\% in patients with uncommon mutations (excluding T790M/exon 20 insertions). Median DOR was 15.1 months (95\% Cl 12.4-21.4 months). Cancer-related symptoms were improved/unchanged/worsened in 34-66\%/36-66\%/0-3\% of patients over the first year.

Conclusions: No unexpected safety signals for afatinib were observed. AEs were manageable; the treatment discontinuation rate was low. Afatinib showed encouraging efficacy in a broad patient population including those with brain metastases or tumors harboring uncommon EGFR mutations.

\footnotetext{
* Correspondence: kpark@skku.edu

'Division of Hematology-Oncology, Department of Medicine Samsung

Medical Center, Sungkyunkwan University School of Medicine, 81 Irwon-ro, Gangnam-gu, 06351 Seoul, South Korea

Full list of author information is available at the end of the article
} 
Trials registration: ClinicalTrials.gov NCT01931306; 29/08/2013.

Keywords: Afatinib, NSCLC, EGFR, Uncommon mutations, Brain metastases, Real world

\section{Background}

In Korea, lung cancer is the most common cause of cancer-related death [1]. While non-small-cell lung cancer (NSCLC) is highly heterogeneous, mutations in the epidermal growth factor receptor (EGFR) gene, leading to aberrant EGFR signaling, occur in up to $50 \%$ of Asian patients [2, 3]. Tumors harboring EGFR mutations are highly sensitive to EGFR tyrosine kinase inhibitors (TKIs) [4-6]. Currently, five EGFR TKIs are approved for the treatment of EGFR mutation-positive NSCLC: the first-generation reversible EGFR TKIs, gefitinib and erlotinib; the second-generation irreversible ErbB family blockers, afatinib and dacomitinib, and the thirdgeneration wild-type sparing irreversible EGFR TKI, osimertinib [4-6].

In randomized trials, first-line afatinib has demonstrated improved progression-free survival (PFS) compared with chemotherapy (LUX-Lung 3 and $6[7,8]$ ) and gefitinib (LUX-Lung 7 [9]) in patients with EGFR mutation-positive NSCLC. Of note, in both LUX-Lung 3 and 6 , prespecified analysis demonstrated that afatinib significantly improved overall survival (OS) versus chemotherapy in patients with tumors carrying a Del19 EGFR mutation [10]. In LUX-Lung 7, median OS was numerically longer with afatinib versus gefitinib, but did not achieve statistical significance [11]. Across clinical trials, afatinib was well tolerated [7-9]. Treatmentrelated adverse events (TRAEs) with afatinib were predominantly class-related gastrointestinal and cutaneous events. While certain TRAEs (e.g., diarrhea) were more common than generally observed with first- and thirdgeneration TKIs, they were manageable with dose reductions, which did not compromise clinical activity [12, 13]. Consequently, treatment discontinuations due to TRAEs were rare $(<10 \%)$. Together, these observations support the use of afatinib for patients with EGFR mutation-positive NSCLC. In phase III trials, both dacomitinib (exploratory analysis) [14] and osimertinib [15] have demonstrated prolonged OS benefit versus firstgeneration EGFR TKIs. However, as the efficacy and safety of afatinib, dacomitinib, and osimertinib have never been directly compared in prospective trials, optimal first-line treatment choice remains an open question, particularly in Asian patients, as there was no evidence of OS benefit with osimertinib over erlotinib/ gefitinib in this subgroup. Therefore, it is important to assess the efficacy and safety of EGFR TKIs in broader 'real-world' patient populations that are more representative of routine practice than clinical trials [16]. Here, we describe the results of an expanded access program performed in South Korea.

\section{Methods}

\section{Study design}

This was an open-label, single-arm, expanded access, phase IIIb trial conducted at eight centers in South Korea. The objectives were to evaluate the tolerability and activity of afatinib in EGFR TKI-naïve patients with EGFR mutation-positive NSCLC.

\section{Patients and treatment}

Patients were $\geq 18$ years old with locally advanced or metastatic EGFR mutation-positive NSCLC, were EGFR TKI-naïve (one previous line of chemotherapy was permitted), and had an Eastern Cooperative Oncology Group performance status (ECOG PS) of $0-2$ and adequate organ function. Main exclusion criteria were hypersensitivity to afatinib, hormonal anticancer treatment or radiotherapy within 14 days and surgery within 4 weeks prior to study start, cardiovascular abnormalities, pre-existing interstitial lung disease (ILD), active chronic infections, previous/concomitant malignancies, and symptomatic brain metastases. Patients received oral afatinib $40 \mathrm{mg}$ daily in 28 -day cycles until disease progression, lack of tolerability, or other study withdrawal criteria. Treatment with afatinib was permitted beyond disease progression if deemed beneficial during assessment. Treatment interruptions and dose reductions were permitted for the management of TRAEs (see the Supporting methods section in the Additional file 1).

At each center, ethical approval was given by an Institutional Review Board or and Independent Ethics Committee. The study was performed in accordance with the Declaration of Helsinki, Good Clinical Practice, and local laws. Written informed consent was given by all patients.

\section{Endpoints, assessments and statistical considerations}

The primary endpoint was the frequency of adverse events (AEs), coded using the Medical Dictionary for Regulatory Activities (MedDRA) version 21.1 and graded by the Common Terminology Criteria for Adverse Events (CTCAE) version 3. Treatment-emergent adverse events (TEAEs), TRAEs, and serious AEs (SAEs) were reported. MedDRA preferred terms for AEs of a similar nature were grouped; grouped terms included rash/acne, stomatitis, and renal insufficiency. Other endpoints included PFS, tumor response, and assessment of cancer- 
related symptoms (see the Supporting methods section in the Additional file 1). Cancer-related symptoms were recorded in the electronic case report form based on investigator judgment as either improved, unchanged, or 'worsening of symptoms due to cancer'. Patients were categorized every 4 weeks and at the end-of-treatment (EOT) visit. EGFR mutations were detected according to the methodology at each participating site.

Analyses were performed on all patients who received at least one dose of afatinib (treatment set). KaplanMeier estimates and 95\% confidence intervals (CIs) were calculated for time-to-event endpoints using Greenwood's standard error estimate. Two-sided $95 \%$ CIs were calculated for the overall response rate (ORR) using the exact 95\% Clopper-Pearson CI. Post hoc analyses of treatment outcomes were performed in patient subgroups based on age ( $<65$ years and $\geq 65$ years), presence of brain metastases (yes and no), EGFR mutation status (common [Del19 only or L858R only] and uncommon), and dose interruptions within the first 6 months (yes and no).

\section{Results}

\section{Patients and treatment exposure}

Between August 28, 2013 and September 21, 2018, 91 patients were enrolled and 88 were treated with afatinib (Fig. 1). All patients discontinued treatment, primarily due to disease progression (67\%). Median age was 61 years (range, 37-87). Seventy (80\%) patients had stage IV disease, 27 (31\%) had asymptomatic brain metastases, and 81 (98\%) had an ECOG PS of 0 or 1 (Table 1). Fifty (57\%) patients harbored an EGFR Del19 mutation; 16 (18\%) patients had an uncommon EGFR mutation (Additional file 1: Table S1). Median treatment duration was 15.3 months (range, 0.3-56.1). Forty-nine (56\%) patients had a dose reduction to $30 \mathrm{mg} /$ day. Of these patients, 22 (25\%) had a second dose reduction to $20 \mathrm{mg}$.

\section{Adverse events}

All 88 treated patients had at least one TEAE (Table 2). Grade 3 TEAEs were reported in 55 (63\%) patients (Additional file 1: Table S2). Grade 4 TEAEs were reported in two patients (one bradycardia and one cardiac arrest). TEAEs leading to dose-reductions were reported in 49 (56\%) patients. The most prevalent reasons for dose reduction were diarrhea (23\%), rash/acne (18\%), and stomatitis (11\%). TEAEs leading to death were reported in seven patients including two with neoplasm progression, two respiratory failure, and one each of dyspnea, hydrocephalus, and death (MedDRA preferred term). SAEs were reported in 37 (42\%) patients; 17 (19\%) patients had grade 3 SAEs and two (2\%) had grade 4 SAEs (Table 2). Eight (9\%) patients had treatment-related SAEs.

TRAEs were reported in 87 (99\%) patients; 51 (58\%) experienced a grade 3 TRAE (Table 3). No grade 4 or 5 TRAEs were reported. The most common TRAEs were (any grade/grade 3) diarrhea (98\%/22\%), rash/acne (92\%/ $20 \%)$, and stomatitis (76\%/15\%). Most TRAEs occurred soon after initiation of therapy and were managed with supportive measures and/or reduction of dose. The

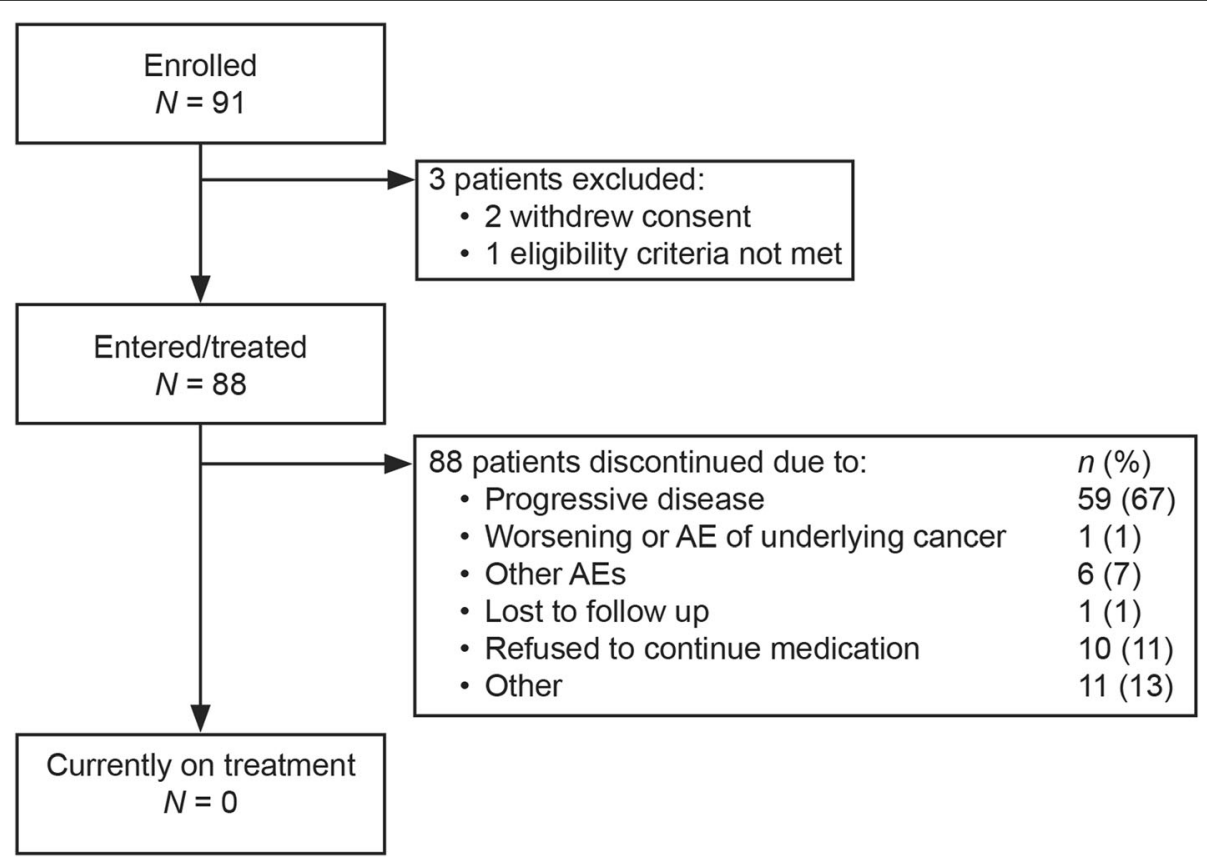

Fig. 1 Patient disposition. (AE: adverse event) 
Table 1 Patient baseline and disease characteristics

\begin{tabular}{|c|c|}
\hline Characteristic & $\begin{array}{l}\text { Treatment Set } \\
N=88\end{array}$ \\
\hline \multicolumn{2}{|l|}{ Age } \\
\hline Median (range), years & $61(37-87)$ \\
\hline$<65$ & $53(60)$ \\
\hline$\geq 65$ & $35(40)$ \\
\hline$\geq 75$ & $5(6)$ \\
\hline \multicolumn{2}{|l|}{ Sex } \\
\hline Female & $46(52)$ \\
\hline Male & $42(48)$ \\
\hline \multicolumn{2}{|l|}{ Smoking status } \\
\hline Never & $55(63)$ \\
\hline Ex-smoker & $27(31)$ \\
\hline Current smoker & $6(7)$ \\
\hline \multicolumn{2}{|l|}{ ECOG PS score } \\
\hline 0 & $15(17)$ \\
\hline 1 & $71(81)$ \\
\hline 2 & $2(2)$ \\
\hline \multicolumn{2}{|l|}{ Tumor histology } \\
\hline Predominantly adenocarcinoma & $87(99)$ \\
\hline Predominantly squamous & $1(1)$ \\
\hline \multicolumn{2}{|l|}{ Clinical stage at initial diagnosis } \\
\hline IA & $7(8)$ \\
\hline IB & $4(5)$ \\
\hline$\| \mathrm{A}$ & $1(1)$ \\
\hline$\| \mathrm{B}$ & $1(1)$ \\
\hline$\| I I A$ & $2(2)$ \\
\hline$\| \mathrm{IIB}$ & $3(3)$ \\
\hline IV & $70(80)$ \\
\hline \multicolumn{2}{|l|}{ Metastases } \\
\hline Any & $86(98)$ \\
\hline Brain & $27(31)$ \\
\hline \multicolumn{2}{|l|}{ EGFR mutation categories } \\
\hline Del19 & $51(58)$ \\
\hline L858R & $27(31)$ \\
\hline Exon 20 insertions & $3(3)$ \\
\hline L861Q & $6(7)$ \\
\hline G719X & $4(5)$ \\
\hline T790M & $2(2)$ \\
\hline S7681 & 0 \\
\hline Other & $2(2)$ \\
\hline \multicolumn{2}{|l|}{ EGFR mutation } \\
\hline Common & $72(82)$ \\
\hline Uncommon & $16(18)$ \\
\hline Any previous systemic chemotherapies & $30(34)$ \\
\hline
\end{tabular}

ECOG PS Eastern Cooperative Oncology Group performance status, EGFR epidermal growth factor receptor Data are $n(\%)$ unless otherwise stated 
Table 2 Summary of TEAEs independent of relatedness

\begin{tabular}{ll}
\hline AE & $\begin{array}{l}\text { Treatment Set } \\
(\mathbf{N}=\mathbf{8 8})\end{array}$ \\
\hline Any AE & $88(100)$ \\
Leading to dose reduction & $49(56)$ \\
Leading to discontinuation & $8(9)$ \\
SAE & $37(42)$ \\
Fatal & $7(8)$ \\
Immediately-life threatening & $1(1)$ \\
Disability incapacity & 0 \\
Requiring hospitalization & $37(42)$ \\
Prolonging hospitalization & $3(3)$ \\
Congenital anomaly & 0 \\
Other & $2(2)$ \\
Highest CTCAE grade & \\
Grade 1 & $2(2)$ \\
Grade 2 & $22(25)$ \\
Grade 3 & $55(63)$ \\
Grade 4 & $2(2)$ \\
Grade 5 & $7(8)$ \\
\hline AE &
\end{tabular}

AE adverse event, CTCAE Common Terminology Criteria for Adverse Events, SAE serious adverse event, TEAE treatment-emergent adverse events Data shown are $n(\%)$

onset of treatment-related diarrhea and rash/acne occurred within 1 week of initiation in 70 and $40 \%$ of cases, respectively; supportive treatment was administered in 84 and $80 \%$ of cases, respectively. Four (5\%) patients discontinued afatinib due to TRAEs: grade 3 decreased appetite, generalized edema, ILD, and paronychia, respectively. There were no treatment-related deaths.

\section{Patient outcomes and subgroup analysis}

Treatment outcomes are summarized in Table 4. Overall median PFS was 17.0 months (95\% CI 12.9-23.3 months; Fig. 2A). Median PFS was 20.2 months (95\% CI 14.227.0 months) in patients who received first-line afatinib $(n=66)$. The ORR was $81 \%$; median duration of response (DOR) was 15.1 months (95\% CI 12.4-21.4 months). Fifty-nine (67\%) patients had responded within 8 weeks.

Post hoc analysis of PFS in patient subgroups is summarized in Table 5. In patients with brain metastases $(n=27)$, median PFS was 14.0 months (95\% CI 11.0 22.1 months; Fig. 2B). In patients with brain metastases and common EGFR mutations $(n=24)$, median PFS was 14.1 months (95\% CI 11.7-22.8 months). The ORR in patients with brain metastases was $89 \%$. All responses occurred within 8 weeks. The median DOR was 12.2 months (95\% CI 9.2-20.3 months). In patients with uncommon EGFR mutations (any uncommon mutation: $n=16$; exon 20 insertions: $n=3$; T790M: $n=2$; L861Q:
Table 3 Treatment-related adverse events

\begin{tabular}{|c|c|c|}
\hline \multirow[t]{2}{*}{$\mathrm{AE}$} & \multicolumn{2}{|c|}{$\begin{array}{l}\text { Treatment Set } \\
(N=88)\end{array}$} \\
\hline & Grade $3^{b}$ & All Grades \\
\hline Any TRAE & $51(58)$ & $87(99)$ \\
\hline Diarrhea & $19(22)$ & $86(98)$ \\
\hline Rash/acne ${ }^{a}$ & $18(20)$ & $81(92)$ \\
\hline Stomatitis $^{a}$ & $13(15)$ & $67(76)$ \\
\hline Pruritus & $2(2)$ & $40(45)$ \\
\hline Paronychia $^{a}$ & $8(9)$ & $36(41)$ \\
\hline Nail disorder & $3(3)$ & $30(34)$ \\
\hline Decreased appetite & $5(6)$ & $20(23)$ \\
\hline Dry skin & 0 & $18(20)$ \\
\hline Nasal inflammation & 0 & $9(10)$ \\
\hline Palmar-plantar erythrodysesthesia syndrome & $1(1)$ & $8(9)$ \\
\hline Nausea & $1(1)$ & $7(8)$ \\
\hline Abdominal pain upper & 0 & $5(6)$ \\
\hline Alopecia & 0 & $5(6)$ \\
\hline Fatigue & $2(2)$ & $5(6)$ \\
\hline Rhinorrhea & 0 & $5(6)$ \\
\hline Scab & 0 & $5(6)$ \\
\hline Skin hyperpigmentation & 0 & $5(6)$ \\
\hline
\end{tabular}

$A E$ adverse event, CTCAE Common Terminology Criteria for Adverse Events, MedDRA Medical Dictionary for Regulatory Activities, TRAE treatment-related adverse event

Shown are $n$ (\%) TRAEs in $>5 \%$ of patients at any grade in the patient treatment set. TRAEs are shown by MedDRA version 21.1 preferred terms and

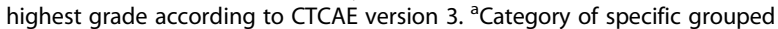

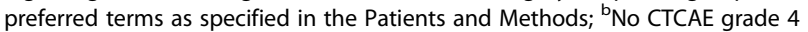
or 5 TRAEs were reported

Table 4 Summary of treatment outcome

\begin{tabular}{ll}
\hline Parameter & $\begin{array}{l}\text { Treatment Set } \\
\mathbf{N}=\mathbf{8 8}\end{array}$ \\
\hline PFS & $70(80)$ \\
Patients who progressed or died, $n$ (\%) & $17.0[12.9-23.3]$ \\
Median, months [95\% Cl] & \\
Tumor response, $n$ (\%) & \\
Best overall response & $2(2)$ \\
$\quad$ Complete response & $69(78)$ \\
$\quad$ Partial response & $12(14)$ \\
$\quad$ Stable disease & $2(2)$ \\
$\quad$ Progressive disease & $3(3)$ \\
$\quad$ Not evaluable & $71(80.7)$ [70.9-88.3] \\
ORR, $n$ (\%) [95\% Cl] & \\
Disease control & $83(94.3)$ [87.2-98.1] \\
DCR, $n$ (\%) [95\% CI] & 18.3 [13.6-23.7] \\
Duration of disease control, months [95\% Cl]
\end{tabular}

$C l$ confidence interval, $D C R$ disease control rate, ORR objective response rate, PFS progression-free survival 
a

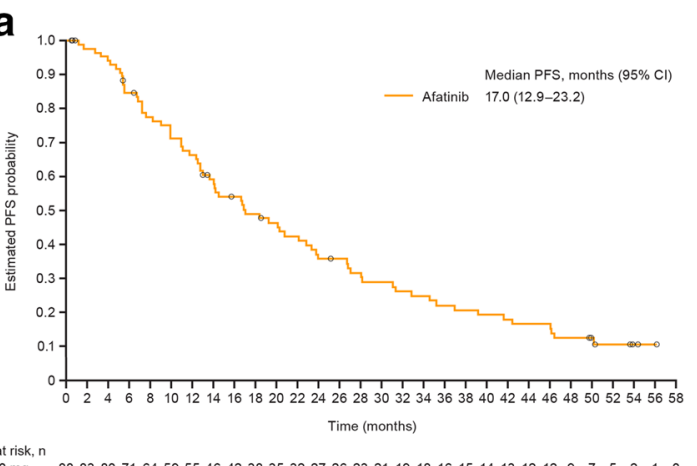

$\begin{aligned} & \text { Patients at risk, n } \\ & \text { Afatinib } 40 \mathrm{mg}\end{aligned} 88838071645955464238353227262321191816151413121297 \quad 7 \quad 5210$

b

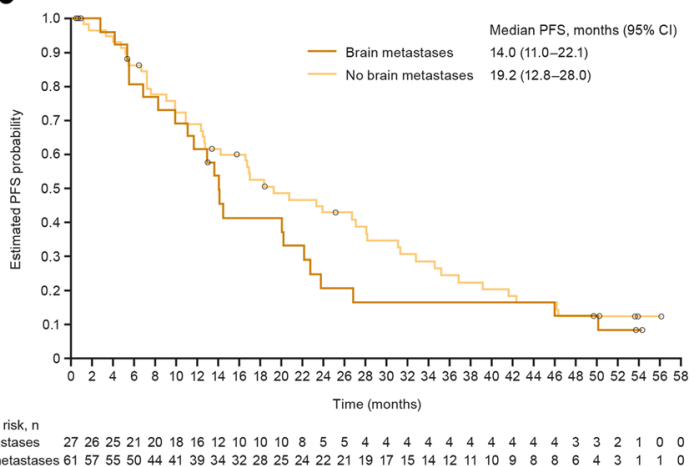

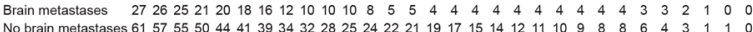

\section{C}

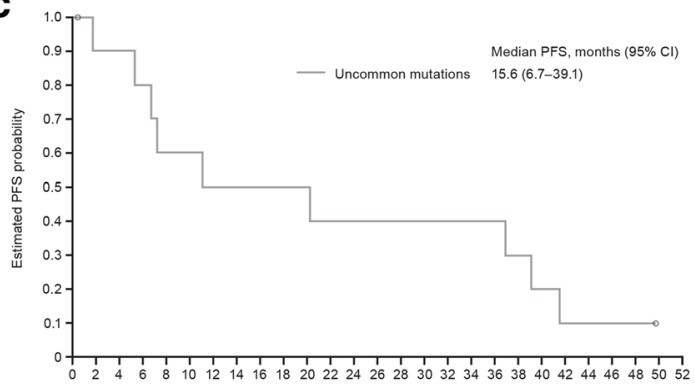
Time (months)

Patients at risk,

d

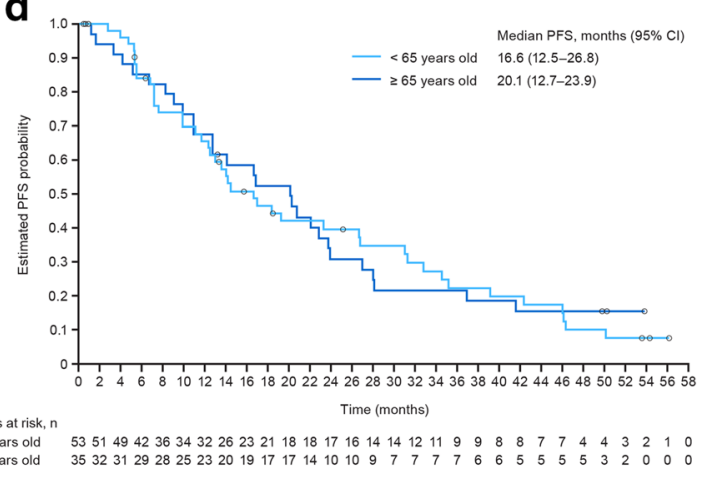

Fig. 2 Progression-free survival in (a) all treated patients. (b) Patients with or without brain metastases at baseline. (c) Patients with uncommon EGFR mutations (excluding T790M or exon 20 insertions). (d) Patients aged $<65$ or $\geq 65$ years. (Cl: confidence interval; PFS: progression-free survival)

$n=6$; G719X: $n=4$; other: $n=2$ ), median PFS was 9.0 months (95\% CI 5.5-20.2 months). Median PFS in patients with G719X or L861Q mutations was 15.6 months (95\% CI 6.7-39.1 months; Fig. 2C). In these patients, the ORR was 55\% and the DOR was 17.2 months (95\% CI 9.2-35.1 months). Patients who were $\geq 65$ years old had similar PFS to those aged $<65$ years old (Fig. 2D).

\section{Cancer-related symptoms}

Over the first year of treatment, the maximum percentage of patients deemed to have improved symptoms was $66 \%$ (week 8) and the minimum percentage was $34 \%$ (week 52; Fig. 3). Patients deemed to have unchanged symptoms ranged from $36 \%$ (week 8) to $66 \%$ (week 36 ). A maximum of $3 \%$ of patients had worsening of symptoms due to cancer. At the EOT, 1\% of patients had improved symptoms, $72 \%$ had unchanged symptoms, and $27 \%$ had a worsening of symptoms due to cancer.

\section{Discussion}

Real-world data are increasingly recognized by regulatory bodies as an important source of information for the monitoring the safety of approved agents, and to support approvals of agents in development [16]. In this study, patient characteristics were similar to those previously reported in studies of EGFR TKIs used in routine clinical practice in Asia, including Korea [17]. The present study included subsets that are generally underrepresented in clinical trials, such as patients with central nervous system (CNS) involvement (31\%) and patients with uncommon EGFR mutations (18\%). In this diverse cohort of patients, the tolerability profile of afatinib was predictable and in line with previous randomized controlled trials [7-9] and real-world studies [16, 18]. However, the rate of TRAEs with afatinib in the current study was higher than observed in randomized controlled trials, possibly reflecting the heterogeneity of patients included the study. While the most common TRAEs were EGFR TKI class-related toxicities (diarrhea, rash/acne and stomatitis) and were not unexpected, the overall rate of grade $\geq 3$ TRAEs was $58 \%$ compared with $31-49 \%$ in the LUX Lung 3, 6 and 7 studies (diarrhea: 5-14\%; rash/acne: 9-16\%; stomatitis: 4-9\%). As expected, given the existence of multiple tablet strengths and previous clinical experience, dose reductions due to AEs were common (56\%). Previous analyses of clinical trials [12, 13], and real-world observations [19] have demonstrated that dose reductions of afatinib facilitate 
Table 5 PFS in patient subgroups

\begin{tabular}{|c|c|c|}
\hline \multirow{2}{*}{$\frac{\text { Category }}{\text { Age, years }}$} & \multicolumn{2}{|l|}{ Patient Subgroup } \\
\hline & $<65$ years & $\geq 65$ years \\
\hline N & 53 & 35 \\
\hline Patients who progressed or died, $n(\%)$ & $42(79)$ & $28(80)$ \\
\hline Median PFS, months (95\% Cl) & $16.6(12.5-26.8)$ & $20.1(12.7-23.9)$ \\
\hline Brain metastases at screening & Yes & No \\
\hline $\mathrm{N}$ & 27 & 61 \\
\hline Patients who progressed or died, $n(\%)$ & $23(85)$ & $47(77)$ \\
\hline Median PFS, months (95\% Cl) & $14.0(11.0-22.1)$ & $19.2(12.8-28.0)$ \\
\hline EGFR mutation type ${ }^{a}$ & Common & Uncommon \\
\hline N & 72 & 16 \\
\hline Patients who progressed or died, $n(\%)$ & $56(78)$ & $14(88)$ \\
\hline Median PFS months, (95\% Cl) & $19.2(14.2-23.9)$ & $9.0(5.5-20.2)$ \\
\hline Afatinib line of therapy & First-line & Second-line \\
\hline N & 66 & 22 \\
\hline Patients who progressed or died, $n(\%)$ & $50(76)$ & $20(91)$ \\
\hline Median PFS, months (95\% Cl) & $20.2(14.2-27.0)$ & $12.9(7.2-26.7)$ \\
\hline Patients with an afatinib dose reduction ${ }^{b}$ & No & Yes \\
\hline N & 54 & 34 \\
\hline Patients who progressed or died, $n(\%)$ & $41(76)$ & $29(85)$ \\
\hline Median PFS, months (95\% Cl) & $20.2(13.6-31.3)$ & $14.2(11.7-22.1)$ \\
\hline
\end{tabular}

Cl confidence interval, EGFR epidermal growth factor receptor, PFS progression-free survival

${ }^{a}$ Common mutations indicates patients whose tumors harbor EGFR exon 19 deletions only or L858R substitutions only: uncommon mutations indicates patients

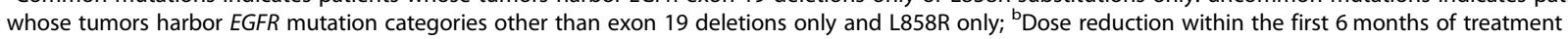

the management of TRAEs without significantly affecting activity. The rate of permanent treatment discontinuation due to TRAEs in the current study was low (5\%) and was comparable to other studies performed in routine clinical practice $(\leq 5 \%)$ and randomized clinical trials, $(6-8 \%)$, suggesting that the use of tolerability- guided dose adjustment in real-world clinical practice can help mitigate common TRAEs [7-9, 16].

In the current study, afatinib stabilized or improved on-treatment cancer-related symptoms in the majority patients. These observations are consistent with clinical trials. For example, in LUX-Lung 3 and 6, afatinib

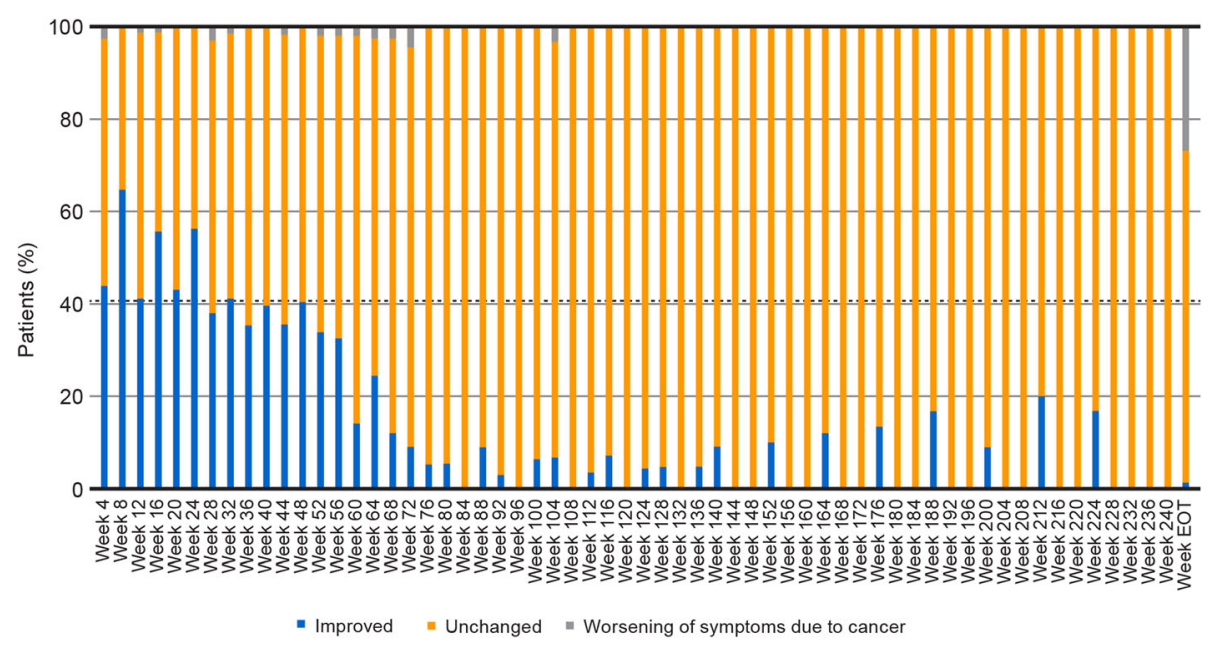

Fig. 3 Change in cancer-related symptoms while on treatment according to the investigator. (EOT: end of treatment) 
improved global health status and quality of life (QoL) versus chemotherapy and conferred better control of certain key symptoms $[20,21]$. Of note, nearly three quarters of patients treated with afatinib had stable, or improved symptoms at the EOT, suggesting that the majority of patients would be sufficiently fit enough to undertake subsequent treatment. This assertion is supported by recent pooled analysis of LUX-Lung 3, 6, and 7 which showed that approximately $70 \%$ of patients treated with first-line afatinib subsequently received further systemic therapy [13]. Uptake of subsequent therapy was around $90 \%$ in countries with comprehensive reimbursement policies.

In this study, afatinib demonstrated encouraging activity in Korean patients with a median PFS of 17.0 months and an ORR of $81 \%$. Sixty-seven percent of patients responded within 8 weeks. These findings generally compare favorably with afatinib activity reported in Asian patients treated in routine clinical practice (median PFS 12.2-19.1 months) [16] and in LUX-Lung 6 (median PFS 11.0 months, ORR 67\%) [8]. Afatinib was observed in patient subgroups, including those with CNS metastases, rare EGFR mutations, and the elderly ( $\geq 65$ years). In patients with uncommon mutations, median PFS was 9.0 months (15.6 months when patients with T790M or exon 20 insertions were excluded). These data are in line with other studies. Preclinical data indicate that afatinib has a broad inhibitory profile against a wide range of EGFR mutations, including compound mutations [22]. Indeed, some categories of uncommon mutations, such as exon 18 mutations, appear to be more sensitive to second-generation EGFR TKIs than first- or thirdgeneration EGFR TKIs in vitro, suggesting that afatinib could be a preferred treatment option in this setting [23]. In a retrospective analysis of LUX-Lung 2, 3, and 6, median PFS with afatinib in patients with rare EGFR exon 18-21 mutations was 10.7 months [24]. Based on these data, afatinib's label was broadened to include tumors with uncommon activating EGFR mutations, including G719X, L861Q, and S768I. Activity of afatinib against these mutations has also been demonstrated in other 'real-world' Asian studies [16]. Osimertinib has also demonstrated activity against uncommon activating EGFR mutations in a single-arm phase II study [25]. Treatment options for exon 20 mutations remain an unmet need, but several agents are in clinical development such as poziotinib and mobocertinib which has shown promise in phase II trials [26, 27].

Recent preclinical data indicate that the CNS penetration of different EGFR TKIs varies and the blood-brainbarrier is more permeable to osimertinib than first- and second-generation EGFR TKIs [28]. Accordingly, subanalysis of the phase III FLAURA trial demonstrated greater CNS activity with osimertinib than erlotinib or gefitinib [29]. Although no head-to-head data versus osimertinib are available, clinical studies have shown that afatinib is also active in patients with EGFR mutationpositive NSCLC and CNS metastases [16,30]. The current study also demonstrated encouraging activity of afatinib (median PFS 14.0 months, ORR 89\%) in patients with CNS metastases $(n=27)$. Preclinical studies have demonstrated that afatinib can cross the blood brain barrier so that pharmacologically relevant concentrations reach brain lesions. Indeed, activity against CNS lesions has been demonstrated in patients [31,32]. Also, data indicate that afatinib may be able to protect against CNS progression. Competing risk analysis of LUX-Lung 3 and 6 showed that 24-month risk of de novo CNS progression was 5\% and risk of non-CNS progression was 71\% [31].

This study has a number of weaknesses. As it was a single-arm, exploratory study with a small sample size, data should be interpreted with caution. Also, mutational analysis of tumors at the point of acquired resistance was not mandated in this study and postprogression therapy was not documented. However, data from other studies indicate that the T790M resistance mutation emerges in around $50-70 \%$ of afatinib-treated tumors [33-35], with particularly high detection rates if sensitive plasma-based assays are used [36]. Given that osimertinib is highly active against T790M-positive tumors [37], a sequential regimen of afatinib followed by osimertinib could be considered in many patients with EGFR mutation-positive NSCLC, which may delay the requirement for chemotherapy. In a recent global observational study of 203 patients, this sequence conferred median OS of 41.3 months (90\% CI 36.8-46.3 months) and median time to treatment failure of 28.1 months (90\% CI 26.8-30.3 months) [38]. Further data are required regarding outcomes with afatinib, or dacomitinib, followed by osimertinib, both in clinical trial and realworld settings. In this regard, data from the ongoing phase 2 trials, Heat on Beat (afatinib versus osimertinib [39]), CAPLAND (NCT04811001; dacomitinib/osimertinib versus osimertinib/dacomitinib) and NCT03810807 (dacomitinib followed by osimertinib/chemotherapy versus osimertinib followed by dacomitinib/chemotherapy) are eagerly anticipated. Of note, a recent phase 2 trial of 12 patients indicated that dacomitinib has limited activity on patients who progress on first-line osimertinib (ORR: 17\%; median PFS: 1.8 months) [40]. Ultimately, consideration of sequential EGFR TKI regimens will require routine testing for T790M at the point of acquired resistance. Recent real-world evidence in the USA suggests that T790M testing rates may be low $(<20 \%)$ in an everyday clinical practice setting [41], although this will vary from country to country. Testing rates may be improved in the future with implementation of liquid biopsy methodologies [42]. 
In conclusion, afatinib administered to Korean patients treated in routine clinical practice was well tolerated with no unexpected safety signals. TRAEs were detected early, usually within the first few weeks of treatment, predictable, and manageable. Active management of AEs facilitated the encouraging clinical activity of afatinib observed in this study. Afatinib was active in the overall cohort and in selected patient subgroups including those with uncommon EGFR mutations or asymptomatic brain metastases at baseline.

\section{Abbreviations}

AE: Adverse event; CNS: Central nervous system; CTCAE: Common Terminology Criteria for Adverse Events; Cl: Confidence interval; DOR: Duration of response; ECOG PS: Eastern Cooperative Oncology Group performance status; EOT: End-of-treatment; EGFR: Epidermal growth factor receptor; ILD: Interstitial lung disease; MedDRA: Medical Dictionary for Regulatory Activities; NSCLC: Non-small cell lung cancer; ORR: Overall response rate; OS: Overall survival; PFS: Progression-free survival; QoL: Quality of life; SAEs: Serious adverse events; TEAEs: Treatment-emergent adverse events; TRAEs: Treatment-related AEs; TKIs: Tyrosine kinase inhibitors

\section{Supplementary Information}

The online version contains supplementary material available at https://doi. org/10.1186/s12885-021-08445-9.

Additional file 1: Supporting methods. Table S1. EGFR mutations in the treated set. Table S2. Treatment-emergent adverse events.

\section{Acknowledgments}

We thank the patients, their families, the investigators, and staff who participated in the study. Medical writing support for the development of this manuscript, under the direction of the authors, was provided by Lynn Pritchard, of Ashfield MedComms, an Ashfield Health company, and funded by Boehringer Ingelheim.

\section{Authors' contributions}

KP: Study concepts, study design, data acquisition, data analysis and interpretation, manuscript preparation, manuscript editing, and manuscript review. JSK: Data acquisition, manuscript editing, and manuscript review. JHK. Data acquisition, manuscript editing, and manuscript review. YCK: Data acquisition, manuscript editing, and manuscript review. HGK: Data acquisition, manuscript editing, and manuscript review. EKC: Data acquisition, manuscript editing, and manuscript review. JYJ: Data acquisition, manuscript editing, and manuscript review. MK: Study design, quality control of data and algorithms, data analysis and interpretation, statistical analysis, manuscript preparation, manuscript editing, and manuscript review. AM: Study design, quality control of data and algorithms, data analysis and interpretation, statistical analysis, manuscript preparation, manuscript editing, and manuscript review. JHK: Study concepts, data acquisition, manuscript editing, and manuscript review. The author(s) read and approved the final manuscript.

\section{Funding}

This work was supported by Boehringer Ingelheim.

\section{Availability of data and materials}

The datasets used and/or analyzed during the current study are available from the corresponding

author on reasonable request. If necessary, documents will be redacted and deidentified to protect confidentiality of study participants and personnel. Further details are available at https://trials.boehringer-ingelheim.com/data_sharing/ sharing.html\#accordion-1-2. Researchers should use https:/vivli.org/ to request access to raw data from this study.

\section{Declarations}

\section{Ethics approval and consent to participate}

At each center, ethical approval was given by an Institutional Review Board or and Independent Ethics Committee. All experimental protocols were approved by the Independent Ethics Committee of the Samsung Medical Centre, Seoul, South Korea on 16th August 2013. The study was performed in accordance with the Declaration of Helsinki, Good Clinical Practice, and local laws. Written informed consent was given by all patients.

\section{Consent for publications}

Not applicable.

\section{Competing interests}

KP has received personal fees from Amgen, Astellas, AstraZeneca, Boehringer Ingelheim, Clovis, Daiichi Sankyo, Eli Lilly, Hanmi, Kyowa Hakko Kirin, Incyte, LOXO, Merck KGaA, Merck Sharp \& Dohme, Ono, Novartis, and Roche; and research funding from AstraZeneca and Merck Sharp \& Dohme. YCK reports grants from Boehringer Ingelheim and AstraZeneca, outside the submitted work. MK and AM are employees of Boehringer Ingelheim. JHK reports personal fees from Boehringer Ingelheim, grants from AstraZeneca, Ono, CKD, and Astellas, grants and personal fees from YooHan, and personal fees from Merck Sharp \& Dohme outside the submitted work. All other authors declare that they have no competing interests.

\section{Author details}

'Division of Hematology-Oncology, Department of Medicine Samsung Medical Center, Sungkyunkwan University School of Medicine, 81 Irwon-ro, Gangnam-gu, 06351 Seoul, South Korea. ²Department of Internal Medicine, Seoul Metropolitan Government Seoul National University Boramae Medical Center, Seoul, South Korea. ${ }^{3} \mathrm{CHA}$ Bundang Medical Center, CHA University, Gyeonggi-do, Seongnam, South Korea. ${ }^{4}$ Chonnam National University Medical School, CNU Hwasun Hospital, Gwangju, South Korea. ${ }^{5}$ Department of Internal Medicine, Gyeongsang National University College of Medicine and Gyeongsang National University Changwon Hospital, Changwon, South Korea. ${ }^{6}$ Gil Medical Center, Gachon University College of Medicine, Incheon, South Korea. 'Bucheon St Mary's Hospital, The Catholic University of Korea, Bucheon, South Korea. ${ }^{8}$ Boehringer Ingelheim Korea Ltd, Seoul, South Korea. ${ }^{9}$ Boehringer Ingelheim International $\mathrm{GmbH}$, Ingelheim am Rhein, Germany. ${ }^{10}$ Department of Internal Medicine, Seoul St. Mary's Hospital, The Catholic University of Korea, Seoul, South Korea.

Received: 13 January 2021 Accepted: 28 May 2021

Published online: 12 July 2021

\section{References}

1. Jung KW, Won YJ, Kong HJ, Lee ES. Prediction of cancer incidence and mortality in Korea, 2019. Cancer Res Treat 2019;51(2):431-437. https://doi. org/10.4143/crt.2019.139.

2. Chan BA, Hughes BG. Targeted therapy for non-small cell lung cancer: current standards and the promise of the future. Transl Lung Cancer Res 2015;4(1):36-54. https://doi.org/10.3978/j.issn.2218-6751.2014.05.01.

3. Han B, Tjulandin S, Hagiwara K, Normanno N, Wulandari L, Laktionov K, et al EGFR mutation prevalence in Asia-Pacific and Russian patients with advanced NSCLC of adenocarcinoma and non-adenocarcinoma histology: the IGNITE study. Lung Cancer 2017;113:37-44. https://doi.org/10.1016/j. lungcan.2017.08.021

4. Wu YL, Planchard D, Lu S, Sun H, Yamamoto N, Kim DW, et al. Pan-Asian adapted clinical practice guidelines for the management of patients with metastatic non-small-cell lung cancer: a CSCO-ESMO initiative endorsed by JSMO, KSMO, MOS, SSO and TOS. Ann Oncol 2019;30(2):171-210. https://doi. org/10.1093/annonc/mdy554.

5. Planchard D, Popat S, Kerr K, Novello S, Smit EF, Faivre-Finn C, et al. Metastatic non-small cell lung cancer: ESMO clinical practice guidelines for diagnosis, treatment and follow-up. Ann Oncol. 2018;29(4_suppl):iv192iv237. https://doi.org/10.1093/annonc/mdy275.

6. Hanna N, Johnson D, Temin S, Baker S, Jr., Brahmer J, Ellis PM, et al. Masters G Systemic therapy for stage IV non-small-cell lung cancer: American Society of Clinical Oncology clinical practice guideline update. J Clin Oncol 2017;35(30):3484-3515. https://doi.org/10.1200/JCO.2017.74.6065. 
7. Sequist LV, Yang JC, Yamamoto N, O'Byrne K, Hirsh V, Mok T, et al. Phase II study of afatinib or cisplatin plus pemetrexed in patients with metastatic lung adenocarcinoma with EGFR mutations. J Clin Oncol 2013;31(27):33273334. https://doi.org/10.1200/JCO.2012.44.2806.

8. Wu YL, Zhou C, Hu CP, Feng J, Lu S, Huang Y, et al., Geater SL Afatinib versus cisplatin plus gemcitabine for first-line treatment of Asian patients with advanced non-small-cell lung cancer harbouring EGFR mutations (LUXlung 6): an open-label, randomised phase 3 trial. Lancet Oncol. 2014;15(2): 213-222. https://doi.org/10.1016/S1470-2045(13)70604-1.

9. Park K, Tan EH, O'Byrne K, Zhang L, Boyer M, Mok T, et al. Afatinib versus gefitinib as first-line treatment of patients with EGFR mutation-positive nonsmall-cell lung cancer (LUX-lung 7): a phase 2B, open-label, randomised controlled trial. Lancet Oncol. 2016;17(5):577-589. https://doi.org/10.1016/ S1470-2045(16)30033-X.

10. Yang JC, Wu YL, Schuler M, Sebastian M, Popat S, Yamamoto N, et al. Afatinib versus cisplatin-based chemotherapy for EGFR mutation-positive lung adenocarcinoma (LUX-lung 3 and LUX-lung 6): analysis of overall survival data from two randomised, phase 3 trials. Lancet Oncol. 2015;16(2): 141-151. https://doi.org/10.1016/S1470-2045(14)71173-8.

11. Paz-Ares L, Tan EH, O'Byrne K, Zhang L, Hirsh V, Boyer M, et al. Afatinib versus gefitinib in patients with EGFR mutation-positive advanced non-small-cell lung cancer: overall survival data from the phase Ilb LUX-lung 7 trial. Ann Oncol 2017;28(2):270-277. https://doi.org/10.1093/annonc/mdw611.

12. Yang JC, Sequist LV, Zhou C, Schuler M, Geater SL, Mok T, et al. Effect of dose adjustment on the safety and efficacy of afatinib for EGFR mutationpositive lung adenocarcinoma: post hoc analyses of the randomized LUXlung 3 and 6 trials. Ann Oncol 2016;27(11):2103-2110. https://doi.org/10.1 093/annonc/mdw322.

13. Schuler M, Tan EH, O'Byrne K, Zhang L, Boyer M, Mok T, et al. First-line afatinib vs gefitinib for patients with EGFR mutation-positive NSCLC (LUXlung 7): impact of afatinib dose adjustment and analysis of mode of initial progression for patients who continued treatment beyond progression. J Cancer Res Clin Oncol 2019;145(6):1569-1579. https://doi.org/10.1007/ s00432-019-02862-x.

14. Mok TS, Cheng Y, Zhou X, Lee KH, Nakagawa K, Niho S, et al. Improvement in overall survival in a randomized study that compared dacomitinib with gefitinib in patients with advanced non-small-cell lung cancer and EGFRactivating mutations. J Clin Oncol 2018;36(22):2244-2250. https://doi.org/1 0.1200/JCO.2018.78.7994

15. Ramalingam SS, Vansteenkiste J, Planchard D, Cho BC, Gray JE, Ohe Y, et al. Overall survival with osimertinib in untreated, EGFR-mutated advanced NSCLC. N Engl J Med 2020;382(1):41-50. https://doi.org/10.1056/NEJMoa1 913662

16. Park K, Wan-Teck Lim D, Okamoto I, Yang JC. First-line afatinib for the treatment of EGFR mutation-positive non-small-cell lung cancer in the 'realworld' clinical setting. Ther Adv Med Oncol. 2019;11:1758835919836374. https://doi.org/10.1177/1758835919836374.

17. Kim Y, Lee SH, Ahn JS, Ahn MJ, Park K, Sun JM. Efficacy and safety of afatinib for EGFR-mutant non-small cell lung cancer, compared with gefitinib or erlotinib. Cancer Res Treat 2019;51(2):502-509. https://doi.org/1 0.4143/crt.2018.117.

18. Lu S, Shih JY, Jang TW, Liam CK, Yu Y. Afatinib as first-line treatment in Asian patients with EGFR mutation-positive NSCLC: a narrative review of real-world evidence. Adv Ther 2021;38:2038-2053. https://doi.org/10.1007/ s12325-021-01696-9.

19. Halmos B, Tan EH, Soo RA, Cadranel J, Lee MK, Foucher P, et al. Impact of afatinib dose modification on safety and effectiveness in patients with EGFR mutation-positive advanced NSCLC: results from a global real-world study (RealGiDo). Lung Cancer 2019;127:103-111. https://doi.org/10.1016/j.lungca n.2018.10.028.

20. Geater SL, Xu CR, Zhou C, Hu CP, Feng J, Lu S, Huang Y, Li W, Hou M, Shi $J H$, Lee KY, Palmer M, Shi Y, Lungershausen J, Wu YL Symptom and quality of life improvement in LUX-lung 6: an open-label phase III study of afatinib versus cisplatin/gemcitabine in Asian patients with EGFR mutation-positive advanced non-small-cell lung cancer. J Thorac Oncol 2015;10(6):883-889. https://doi.org/10.1097/JTO.0000000000000517.

21. Yang JC, Hirsh V, Schuler M, Yamamoto N, O'Byrne KJ, Mok TS, et al. Symptom control and quality of life in LUX-lung 3: a phase III study of afatinib or cisplatin/pemetrexed in patients with advanced lung adenocarcinoma with EGFR mutations. J Clin Oncol 2013;31(27):3342-3350. https://doi.org/10.1200/JCO.2012.46.1764.
22. Kohsaka S, Petronczki M, Solca F, Maemondo M. Tumor clonality and resistance mechanisms in EGFR mutation-positive non-small-cell lung cancer: implications for therapeutic sequencing. Future Oncol 2019;15(6): 637-652. https://doi.org/10.2217/fon-2018-0736.

23. Kobayashi $Y$, Togashi $Y$, Yatabe $Y$, Mizuuchi $H$, Jangchul $P$, Kondo C, et al. EGFR exon 18 mutations in lung cancer: molecular predictors of augmented sensitivity to afatinib or neratinib as compared with first- or third-generation TKls. Clin Cancer Res 2015;21(23):5305-5313. https://doi.org/10.1158/1078-0432.Ccr-15-1046.

24. Yang JC, Sequist LV, Geater SL, Tsai CM, Mok TS, Schuler M, et al. Clinical activity of afatinib in patients with advanced non-small-cell lung cancer harbouring uncommon EGFR mutations: a combined post-hoc analysis of LUX-lung 2, LUX-lung 3, and LUX-lung 6. Lancet Oncol 2015;16(7):830-838. https://doi.org/10.1016/S1470-2045(15)00026-1.

25. Cho JH, Lim SH, An HJ, Kim KH, Park KU, Kang EJ, et al. Osimertinib for patients with non-small-cell lung cancer harboring uncommon EGFR mutations: a multicenter, open-label, phase II trial (KCSG-LU15-09). J Clin Oncol 2020;38(5):488-495. https://doi.org/10.1200/jco.19.00931.

26. Heymach J, Negrao M, Robichaux J, Carter B, Patel A, Altan M, Gibbons D, Fossella F, Simon G, Lam V, Blumenschein G, Tsao A, Kurie J, Mott F, Jenkins D, Mack D, Feng L, Roeck B, Yang Z, Papadimitrakopoulou V, Elamin Y OA02.06 a Phase II trial of poziotinib in EGFR and HER2 exon 20 mutant non-small cell lung cancer (NSCLC). J Thorac Oncol 2018;13(10):S323-S324. https://https://doi.org/10.1016/j.jtho.2018.08.243.

27. Riely GJ, Neal JW, Camidge DR, Spira Al, Piotrowska Z, Costa DB, et al. Activity and safety of mobocertinib (TAK-788) in previously treated nonsmall cell lung cancer with EGFR exon 20 insertion mutations from a Phase 1/2 trial. Cancer Discov (ahead of print). 2021. https://https://doi.org/10.11 58/2159-8290.Cd-20-1598.

28. Colclough N, Chen K, Johnström P, Strittmatter N, Yan Y, Wrigley GL, et al. Cross DAE Preclinical comparison of the blood-brain barrier permeability of osimertinib with other EGFR TKIs. Clin Cancer Res 2021;27(1):189-201. https://doi.org/10.1158/1078-0432.Ccr-19-1871.

29. Reungwetwattana T, Nakagawa K, Cho BC, Cobo M, Cho EK, Bertolini A, Bohnet S, Zhou C, Lee KH, Nogami N, Okamoto I, Leighl N, Hodge R, Mckeown A, Brown AP, Rukazenkov Y, Ramalingam SS, Vansteenkiste J CNS response to osimertinib versus standard epidermal growth factor receptor tyrosine kinase inhibitors in patients with untreated EGFR-mutated advanced non-small-cell lung cancer. J Clin Oncol 2018;36(33):3290-3297. https://doi.org/10.1200/jco.2018.78.3118.

30. Schuler M, Wu YL, Hirsh V, O'Byrne K, Yamamoto N, Mok T, et al. First-line afatinib versus chemotherapy in patients with non-small cell lung cancer and common epidermal growth factor receptor gene mutations and brain metastases. J Thorac Oncol 2016;11(3):380-390. https:/doi.org/10.1016/j.jtho.2015.11.014.

31. Hochmair M. Medical treatment options for patients with epidermal growth factor receptor mutation-positive non-small cell lung cancer suffering from brain metastases and/or leptomeningeal disease. Target Oncol 2018;13(3): 269-285. https://doi.org/10.1007/s11523-018-0566-1.

32. Hochmair M, Holzer S, Burghuber OC. Complete remissions in afatinibtreated non-small-cell lung cancer patients with symptomatic brain metastases. Anti-Cancer Drugs 2016;27(9):914-915. https://doi.org/10.1097/ CAD.0000000000000410.

33. Tanaka K, Nosaki K, Otsubo K, Azuma K, Sakata S, Ouchi H, et al. Acquisition of the T790M resistance mutation during afatinib treatment in EGFR tyrosine kinase inhibitor-naive patients with non-small cell lung cancer harboring EGFR mutations. Oncotarget. 2017;8(40):68123-68130. https://doi. org/10.18632/oncotarget.19243.

34. Yang JC, Ahn MJ, Kim DW, Ramalingam SS, Sequist LV, Su WC, et al. Osimertinib in pretreated T790M-positive advanced non-small-cell lung cancer: AURA study phase II extension component. J Clin Oncol 2017;35(12): 1288-1296. https://doi.org/10.1200/JCO.2016.70.3223.

35. Wu SG, Liu YN, Tsai MF, Chang YL, Yu CJ, Yang PC, Yang JCH, et al. The mechanism of acquired resistance to irreversible EGFR tyrosine kinase inhibitor-afatinib in lung adenocarcinoma patients. Oncotarget. 2016;7(11): 12404-12413. https://doi.org/10.18632/oncotarget.7189.

36. Hochmair MJ, Buder A, Schwab S, Burghuber OC, Prosch H, Hilbe W, et al. Liquid-biopsy-based identification of EGFR T790M mutation-mediated resistance to afatinib treatment in patients with advanced EGFR mutationpositive NSCLC, and subsequent response to osimertinib. Target Oncol 2019;14(1):75-83. https://doi.org/10.1007/s11523-018-0612-z.

37. Mok TS, Wu YL, Ahn MJ, Garassino MC, Kim HR, Ramalingam SS, et al. AURA3 Investigators Osimertinib or platinum-pemetrexed in EGFR T790M- 
positive lung cancer. N Engl J Med 2017;376(7):629-640. https://doi.org/10.1 056/NEJMoa1612674.

38. Hochmair MJ, Morabito A, Hao D, Yang CT, Soo RA, Yang JC, et al. Sequential afatinib and osimertinib in patients with EGFR mutation-positive non-small-cell lung cancer: updated analysis of the observational GioTag study. Future Oncol 2019;15(25):2905-2914. https://doi.org/10.2217/fon-201 9-0346.

39. Morikawa K, Tanaka H, Itani H, Takata S, Watanabe S, Kishi K, et al. Hypothesis generative head-to-head study comparing efficacy of afatinib and osimertinib based on immunological biomarkers in Japanese NSCLC patients with EGFR mutations (heat on beat study). Ther Adv Med Oncol 2020;12:1758835920967254. https://doi.org/10.1177/1758835920967254.

40. Choudhury NJ, Makhnin A, Tobi YY, Daly RM, Preeshagul IR, Iqbal AN, et al. Pilot study of dacomitinib for patients with metastatic EGFR-mutant lung cancers with disease progression after initial treatment with osimertinib. JCO Prec Oncol 2021;5:695-700. https://doi.org/10.1200/po.21.00005.

41. Nadler E, Pavilack M, Espirito JL, Clark J, Fernandes A. Observational study of treatment patterns in patients with epidermal growth factor receptor (EGFR) mutation-positive non-small cell lung cancer after first-line EGFR-tyrosine kinase inhibitors. Adv Ther 2020;37(2):946-954. https://doi.org/10.1007/ s12325-020-01221-4

42. Cecchini MJ, Yi ES. Liquid biopsy is a valuable tool in the diagnosis and management of lung cancer. J Thorac Dis 2020;12(11):7048-7056. https:// doi.org/10.21037/jtd.2020.04.20

\section{Publisher's Note}

Springer Nature remains neutral with regard to jurisdictional claims in published maps and institutional affiliations.

Ready to submit your research? Choose BMC and benefit from:

- fast, convenient online submission

- thorough peer review by experienced researchers in your field

- rapid publication on acceptance

- support for research data, including large and complex data types

- gold Open Access which fosters wider collaboration and increased citations

- maximum visibility for your research: over $100 \mathrm{M}$ website views per year

At BMC, research is always in progress.

Learn more biomedcentral.com/submissions 